\title{
МОДЕЛИ ВЗАИМОДЕЙСТВИЯ УЧАСТНИКОВ РЕКРЕАЦИОННОЙ СФЕРЫ С ПОМОЩЬЮ КОНСАЛТИНГА
}

\author{
А. М. Бархатова \\ Байкальский государственный университет, г. Иркутск, Российская Федерация
}

Информация о статье

Дата поступления

22 мая 2017 г.

Дата принятия к печати 20 ноября 2017 г.

Дата онлайн-размещения 27 ноября 2017 г.

\section{Ключевые слова}

Рекреационная сорера; модель взаимодействия; консалтинг; производитель; потребитель; классическая типология; постклассичекая типология

\begin{abstract}
Аннотация
В статье обосновывается актуальность развития услуг рекреационной сферы, определяются основные ее участники, предлагается рационализация модели взаимодействия между участниками с целью сокращения расходов на каждом этапе развития и извлечения выгоды. В работе также описываются и сравниваются две модели взаимодействия рекреационной сферы: «классическая» модель отображает сложившееся взаимодействие участников рекреационной сфреры, действующее в настоящее время, «постклассическая» модель построена с учетом тенденций развития рекреационной сфреры и новых направлений деятельности. Рассматриваются недостатки и положительные стороны моделей, выводится наиболее эффрективная модель взаимодействия участников рекреационной сферы с помощью консалтинга. «Постклассическая» модель объединяет консультантов рынков «Business to business» (бизнес для бизнеса) и «Business to consumer» (бизнес для потребителя), сокращая тем самым расходы участников и повышая эфффективность работы всей сферы.
\end{abstract}

\section{INTERACTION MODELS OF RECREATIONAL INDUSTRY PARTICIPANTS BY MEANS OF CONSULTING SERVICES}

\author{
Anna M. Barkhatova \\ Baikal State University, Irkutsk, Russian Federation
}

Article info

Received

May 22, 2017

Accepted

November 20, 2017

Available online

November 27, 2017

\section{Keywords}

Recreational industry; interaction model; consulting; manufacturer; consumer; classical typology; post-classical typology

\begin{abstract}
The article proves the importance of the development of recreational industry services, identifies the main participants of the recreational industry. It offers a rational model of interaction between its participants in order to reduce costs at each stage of the development and making profit. Two models of interaction in the recreational industry are described and compared. The «classical» model reflects the current interaction of the recreational industry participants functioning now. The «post-classical» model was developed with consideration of trends in the development of the recreational industry and new fields of activity. The article considers advantages and disadvantages of these models and offers the most efficient model of interaction between the participants of the recreational industry by means of consulting services. The "postclassical» model encompasses B2B and B2C marketing consultants, thereby reducing the participants' costs and increasing the effectiveness of the work of the industry.
\end{abstract}

ному типу экономического развития страны является создание условий для улучшения качества жизни граждан России, в том числе за счет становления инораструктуры отдыха и туризма. Рынок рекреационных услуг удовлетворяет потребности населения в отдыхе и содержательном проведении досуга и функционирует по общим законам мирового 
рынка, являясь составляющей рынка услуг, его видовым компонентом [1, с. 6].

В экономической литературе отмечают следующие характеристики рекреационных услуг:

- восстановление и развитие человеческого капитала;

- воспроизводство производительных сил общества;

- обеспечение экономического роста региона благодаря мощному мультипликативному эфффекту;

- комплексность;

- генерирование новых импульсов социально-экономического роста региона [2].

В настоящее время все больше организаций занимается предоставлением рекреационных услуг. При этом в данной сфере постоянно появляются новые направления и все чаще происходит объединение компаний для наиболее качественного оказания услуг. Компании, которые предлагают рекреационные услуги, нуждаются в покупке сопутствующих товаров для осуществления качественной услуги. Таким образом, обращение производителей услуг к производителям товаров способствует формированию партнерских отношений и обеспечивает комплексность рекреационной сферы. Следует отметить, что в Иркутске доминирует тенденция роста торговых площадей и ввода в эксплуатацию новых торговых объектов. В соответствии с Программой комплексного социальноэкономического развития г. Иркутска на 2008-2020 гг. предполагается наращивание оборота розничной торговли со 148 685,8 до 243162,7 млн р. по инерционному сценарию и с 215 455, 8 до 442 368,6 млн р. по инновационному сценарию развития [3, с. 140-141]. При этом значительная доля населения отдает предпочтение качественному обслуживанию в современных торговых центрах более дешевым товарам в неорганизованных местах торговли. Представим рациональную модель взаимодействия между участниками рекреационных услуг с целью сокращения расходов и извлечения выгоды. Для построения моделей хорошо подойдет классическая и постклассичекая типология.

Использование типологии «классика постклассика» представляет собой традицию отечественной философии науки. Впервые соответствующее разделение было обосновано в статье М. К. Мамардашвили, Э. Ю. Соловьева и В. С. Швырева, посвященной эпистемологическому сопоставлению классической и современной философии, при этом понятие «современная» примени- тельно к фрилософиии имело «неклассическое» и «постклассическое» значение $[4 ; 5]$. В дальнейшем понятия «классика» и «неклассика», как отмечает Н. С. Автономова, стали общеупотребительными [6, с. 32]. Данная типология используется также в качестве инструмента концептуальной реконструкции в ряде социально-гуманитарных наук (социологии, истории, менеджменте и экономике).

Типология классического и постклассического понимания коррелирует с общепризнанным в фрилософии науки выделением научной рациональности, в основе которого лежит различие стилей научного мышления [7, с. 11]. К. Мангейм ввел понятие «стиль мышления», рассматривая его в качестве «объективной мыслительной структуры» [8].

Понятие «стиль научного мышления» стало активно использоваться в отечественной философии науки начиная с конца 1960-х гг. [9-11]. При этом подчеркивается, что интерес к нему был инициирован размышлениями М. Борна, который, в частности, писал: «Я думаю, что существуют какие-то общие тенденции мысли... Будучи знакомым со стилем своего времени, можно сделать некоторые осторожные предсказания. По крайней мере можно отвергнуть идеи, чуждые стилю нашего времени» [12, с. 227].

Таким образом, выделение классического и постклассического подходов имеет под собой фундаментальные социокультурные основания, используемые в построении моделей взаимодействия участников рекреационной сореры.

К рекреационной сфере отнесем традиционную модель оказания услуг (назовем ее «классической»), подразумевающую оказание услуги потребителю через посредников, которые связывают участников [13, с. 153]. В роли таких посредников выступают консультанты рынков «Business to business» (B2B) и «Business to consumer» (В2C). «Классическая» модель отражает согласованные действия цепочки «производитель услуг и товаров - консультанты рынков В2В и В2С - потребитель». Эта модель отображает взаимодействие участников рекреационной сферы, давно сложившееся и действующее в настоящее время.

Вторая модель строится с учетом тенденций развития рекреационной сферы и новых направлений деятельности. Как было отмечено ранее, по словам М. Борна, нужно модернизировать идеи и модели с учетом изменений, происходящих со временем. Таким образом, предложим трансформированную модель (назовем ее «постклассической»), в которой роль консультантов заключается 
в адаптации товаров и услуг производителя к мотивам потребителя и формирование готового рекреационного комплекса. Модель объединяет консультантов рынков В2В и В2С, тем самым сокращая расходы участников и повышая эфффективность работы всей сферы.

Рассмотрим классический подход к созданию модели, который состоит из поэтапной схемы действия участников рекреационной сореры. Основные участники процесса - это производитель услуг, производитель товаров, консультанты, потребитель (рис. 1).

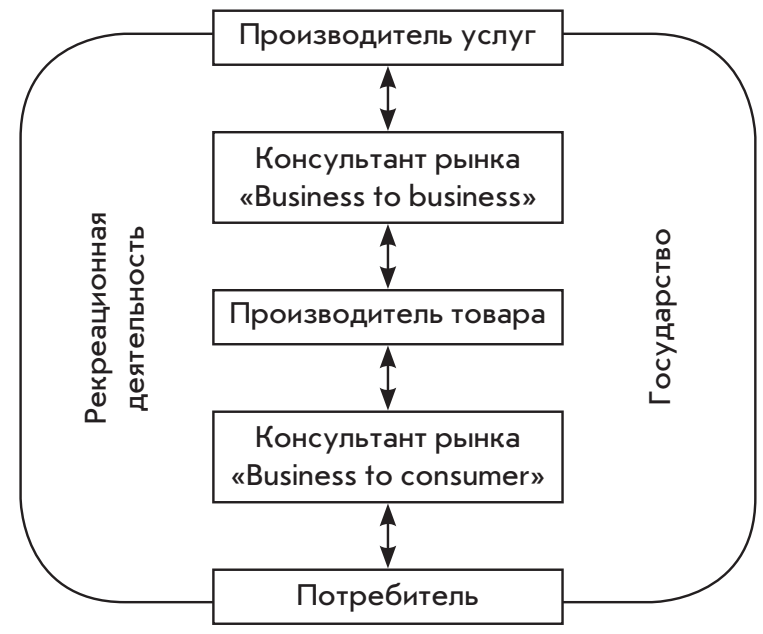

Рис. 1. «Классическая" модель взаимодействия участников рекреационной сферы

Все элементы этой модели являются взаимосвязанными и неразрывными, поэтому рекреационную сфреру можно представить как поэтапный процесс.

Большинство услуг, оказываемых в рекреационной сфере, сопровождают сопутствующие товары. К примеру, купив абонемент на фитнес-услуги, потребитель платит деньги не только за оказанную услугу, но и за сопутствующие товары, необходимые для фитнеса. Соответственно, продажа рекреационных товаров более эффрективна совместно с консалтинговой услугой, благодаря которой потребитель получает информацию о преимуществах товара, правильности его использования и возможном результате. Причем производитель услуги и производитель товара взаимодействуют между собой с помощью консультантов В2В, в роли которых обычно выступают специалисты по закупкам, менеджеры по продажам, маркетологи и другие работники. Все эти специалисты превращаются в инструмент продвижения требований производителей и подыскивают наиболее выгодные условия среди других. Между производителем рекреационного товара и потребителем также есть консуль- тант В2С, который рассказывает о свойствах рекреационного товара, информирует об его использовании для того, чтобы получить результат. В роли таких консультантов могут выступать продавцы магазина, промоперсонал и иные работники организаций. В данном случае консультанты выступают как инструмент продвижения рекреационных товаров и услуг и тем самым влияют на исход потребления и дальнейший спрос.

В представленной модели каждый этап может повлиять на продажи рекреационного товара в лучшую или худшую сторону. Консультанты в данной схеме - это связующие звенья между рынками В2В и В2С, которые разбиты на разные этапы. В момент сотрудничества между производителем товара и услуги всегда присутствует консультант от компании, отвечающий за выбор товара и поставщика. Второй консультант доносит информацию от производителя до потребителя.

Проанализируем выгоды и издержки взаимодействия участников рекреационной сферы в «классической» модели с участием консультанта в роли инструмента продвижения товара или услуги (табл. 1).

\section{Выгоды и издержки взаимодействия участников рекреационной сферы} Таблица 1 в «классической» модели

\begin{tabular}{|c|c|c|}
\hline Участники & Выгоды & Издержки \\
\hline $\begin{array}{l}\text { Производи- } \\
\text { тель товаров } \\
\text { и услуг }\end{array}$ & $\begin{array}{l}\text { Получение } \\
\text { прибыли }\end{array}$ & $\begin{array}{l}\text { Деньги, челове- } \\
\text { ческий капитал, } \\
\text { материальные } \\
\text { ресурсы }\end{array}$ \\
\hline Потребитель & $\begin{array}{l}\text { Получение инфор- } \\
\text { мации }\end{array}$ & Деньги, время \\
\hline Государство & $\begin{array}{l}\text { Налоги, под- } \\
\text { держка модели } \\
\text { здорового образа } \\
\text { жизни }\end{array}$ & $\begin{array}{l}\text { Человеческий } \\
\text { капитал }\end{array}$ \\
\hline $\begin{array}{l}\text { Консуль- } \\
\text { тант как } \\
\text { инструмент } \\
\text { продвижения }\end{array}$ & Прибыль & $\begin{array}{l}\text { Время, челове- } \\
\text { ческий капитал, } \\
\text { материальные } \\
\text { ресурсы }\end{array}$ \\
\hline
\end{tabular}

В «классической» модели производители продвигают свой товар или услугу через дополнительную единицу человеческого капитала - консультанта рекреационной сореры. Производитель тратит деньги на зарплату консультанта рынка В2В (менеджера по продажам, специалиста по государственным закупкам) и расходует материальные ресурсы на организацию и оснащение рабочего места. Аналогично производитель платит консультантам рынка В2С за продвижение рекреационных товаров и услуг, расходуя материальные и денежные ресурсы на point of sales materials 
(POSM) и рекламу. В рассмотренной модели производитель должен обладать человеческими, материальными и денежными ресурсами, так как, инвестируя ресурсы в консультантов, он получает больше прибыли.

Потребитель в данной модели получает инорормацию о товаре или услуге от консультанта В2С и самостоятельно принимает решение о покупке. Потребитель должен обладать денежными и временнымми ресурсами: первые позволяют купить рекреационный товар или услугу, вторые необходимы для поиска и анализа информации, а также для принятия решения о покупке рассматриваемого товара или услуги.

Работоспособность и заинтересованность консультантов этой модели зависит от денежной мотивации производителя, т. е. выплачиваемой прибыли. Для работы консультантов также важны временны́е, человеческие и материальные ресурсы. Временнь́е ресурсы раскрываются через измерение затраченного времени и получаемой прибыли, т. е. консультант не будет заинтересован в затратах своего времени на сделки, которые плохо оплачиваются. Человеческий капитал влияет на количество сотрудников, участвующих в этом процессе, а следовательно, на настроение, самочувствие и трудоспособность работников. Материальные ресурсы организуют рабочую среду сотрудника и открывают возможности взаимодействия и продвижения.

Государство затрачивает лишь человеческий капитал на организацию, поддержание и контроль рекреационной сореры, взамен получая налоги и помощь в пропаганде здорового образа жизни от предприятий и консультантов данной сореры.

Недостатками «классической» модели для производителей являются:

- двойные затраты, заключающиеся в оплате работы каждого консультанта;

- зависимость эфффективности работь консультантов от зарплатной мотивации;

- двойное присутствие консультантов, увеличивающее трудозатраты на их поиски и обучение;

- повышение риска раскрытия коммерческой тайны и важной информации.

Недостатки «классической» модели для потребителя:

- подается информация, выгодная с точки зрения производителя (для продвижения товара и услуги), следовательно, информация, предназначенная для потребителя, является неполной;

- консультирование оказывается только по ограниченному ассортименту услуг и товаров определенной компании.
Таким образом, построенная «классическая» модель взаимодействия участников рекреационной сферы отображает реальную ситуацию в России, и в частности в Иркутске. Консультантов заменяют работники производителей, сопутствующих компаний и точек сбыта. Большинство компаний не имеет партнерских отношений и работает изолированно от других. Участники слабо представляют реальную ситуацию, сложившуюся в рекреационной сфрере. Информация от потребителей долго идет до производителя и искажается на этапах передачи. Производителям неизвестны новые тенденции потребления и непонятна реакция потребителей на предоставляемые услуги или товары, участники слабо взаимодействуют между собой и не оценивают возможности рекреационной сферы.

Исходя из анализа «классической» модели рекреационной сорере необходима улучшенная модель взаимодействия, составленная на основе постклассического подхода.

В «постклассической» модели ключевым звеном является консультант, так как поток информации до потребителя о рекреационном товаре или услуге проходит через него (рис. 2).

\begin{tabular}{|l|c|}
\hline \multicolumn{1}{|c|}{ Производитель рекреационных услуг } \\
\hline & Рекреационная \\
\hline деятельность & \multicolumn{1}{|c|}{ Понсультант } \\
\hline & Производитель \\
\hline
\end{tabular}

\section{Рис. 2. «Постклассическая" модель взаимодействия участников рекреационной сферы}

Производители рекреационных товаров и услуг образуют рекреационную деятельность. На этом же рынке появляется узкоспециализированная консалтинговая компания, которая подбирает производителей по направлениям деятельности, объединяет их усилия и доносит готовую информацию до потребителя. Таким образом, потребителю предлагают уже комплексную услугу, подобранную под его потребности. Следовательно, одна консалтинговая компания объединяет в себе консультантов рынков В2В и В2С.

Выделим выгоды и издержки взаимодействия участников рекреационной сферы в «постклассической» модели, где консультант выступает в качестве основного участника (табл. 2). 
Таблица 2

Выгоды и издержки взаимодействия участников рекреационной сферы в «постклассической» модели

\begin{tabular}{|c|c|c|}
\hline Участники & Выгоды & Издержки \\
\hline $\begin{array}{l}\text { Произ- } \\
\text { водитель } \\
\text { товаров } \\
\text { и услуг }\end{array}$ & $\begin{array}{l}\text { Увеличение прибыли, } \\
\text { развитие бизнеса, на- } \\
\text { лаживание партнерских } \\
\text { связей, имидж соци- } \\
\text { ально ответственной } \\
\text { компании, повышение } \\
\text { качества сервиса }\end{array}$ & Деньги \\
\hline $\begin{array}{l}\text { Потреби- } \\
\text { тель }\end{array}$ & $\begin{array}{l}\text { Получение объективной, } \\
\text { полной, профессио- } \\
\text { нальной, комплексной } \\
\text { информации, сервиса } \\
\text { высокого качества }\end{array}$ & $\begin{array}{l}\text { Деньги, } \\
\text { время }\end{array}$ \\
\hline $\begin{array}{l}\text { Государ- } \\
\text { ство }\end{array}$ & $\begin{array}{l}\text { Налоги, усиленная } \\
\text { поддержка модели здо- } \\
\text { рового образа жизни, } \\
\text { развитие рекреационной } \\
\text { сореры, повышение } \\
\text { качества сервиса }\end{array}$ & $\begin{array}{l}\text { Человече- } \\
\text { ский капитал }\end{array}$ \\
\hline $\begin{array}{l}\text { Консал- } \\
\text { тинговая } \\
\text { органи- } \\
\text { зация как } \\
\text { участник }\end{array}$ & $\begin{array}{l}\text { Прибыль, партнер- } \\
\text { ские связи, имидж } \\
\text { связующей компании } \\
\text { в рекреационной сфрере }\end{array}$ & $\begin{array}{l}\text { Время, че- } \\
\text { ловеческий } \\
\text { капитал, ма- } \\
\text { териальные } \\
\text { ресурсы }\end{array}$ \\
\hline
\end{tabular}

Производители товаров и услуг оплачивают только работу консалтинговой организации, взамен они получают отчетные результаты работы консультантов и выгоды. При таком взаимодействии производители не только повышают продажи товаров и услуг, но и развивают бизнес благодаря оперативной передаче информации от потребителей и рекреационную сферу в целом. Консалтинговая компания способствует строительству партнерских отношений между производителями и объединяет их усилия с помощью комплексного предоставления услуг населению. Подобное комбинирование товаров и услуг помогает подобрать готовое решение для потребителя и улучшить качество сервиса. Кроме того, рассматриваемая модель дает возможность производителям рекреационной сореры активно поддерживать имидж социально ответственной компании и развивать подобные и необходимые для населения направления бизнеса.

Выделенная роль консультанта позволяет потребителям получать профессиональную консультацию стороннего специалиста в рекреационной сфере, который может подобрать необходимые услуги и товары в комплексе, что усиливает эфрфект от потребления и помогает добиться желаемого результата. Взамен потребитель тратит время на консультацию, но при этом сокращает время на самостоятельный поиск информации о товаре или услуге. После принятия решения о покупке потребителю необходимы денежные ресурсы. Возможные затраты денег и времени также оговариваются с консультантом, в результате чего подбирается рациональный вариант затрат располагаемых ресурсов для получения потребителем желаемого результата. Подобранная консультантом комплексная покупка товаров и услуг помогает сэкономить потребителю денежные и временны́е ресурсы. Таким образом, модель уменьшает затраты потребителя и дает ряд весомых выгод для дальнейшего развития рекреационной сферы.

Государство от применения построенной модели также получает ряд преимуществ. Развиваются и поддерживаются государственные программы, направленные на популяризацию здорового образа жизни с помощью работы консультантов рекреационной сореры. Причем развитие этих направлений помогает расширить бизнес производителей и увеличить общую выручку компаний, что приводит к росту собираемости налогов и взносов. В отношении потребителя с помощью «постклассической» модели организуется высокий уровень сервиса, удовлетворяющий запросы населения, соответственно повышается и лояльность к государству. Таким образом, консалтинговая компания организует взаимодействие всех участников рекреационной сореры и помогает государству развивать и поддерживать данное направление бизнеса. Государство расходует только человеческие ресурсы на контроль над этим взаимодействием.

Консалтинговая организация затрачивает человеческий капитал своих сотрудников, в частности их время и усилия на обслуживание потребителей. Затрачиваются также материальные ресурсы, влияющие на окружающую консультанта обстановку, продуктивность его работы и лояльность потребителей. Взамен консалтинговая организация получает прибыль и партнерскую базу производителей, готовых к сотрудничеству и взаимодействию. Растет лояльность потребителей и известность обслуживающей организации среди населения в данной сорере. Таким образом, консалтинговая компания является связующим звеном в рекреационной сорере, она улучшает работу всех участников, развивает партнерские связи, повышает качество обслуживания и создает положительный имидж рекреационной сферы в целом.

Привлечение консалтинговой организации в качестве участника рекреационной сфреры увеличивает выгоды всех ее участников (табл. 3). 
Сравнение «классической» и «постклассической» моделей взаимодействия участников рекреационной сферы

\begin{tabular}{|c|c|c|}
\hline Показатель & «Классическая» модель & «Постклассическая» модель \\
\hline $\begin{array}{l}\text { Схема цепочки } \\
\text { услуги }\end{array}$ & $\begin{array}{l}\text { Строгая последовательность } \\
\text { этапов }\end{array}$ & $\begin{array}{l}\text { Взаимодействие всех участников, причем роль } \\
\text { консультанта ключевая }\end{array}$ \\
\hline Информация & $\begin{array}{l}\text { Инфрормация поэтапно передается } \\
\text { участниками от потребителя } \\
\text { к производителю услуг }\end{array}$ & $\begin{array}{l}\text { Инорормацию сортирует и оперативно передает } \\
\text { другим участникам консультант }\end{array}$ \\
\hline Роль производителя & $\begin{array}{l}\text { Основная (вся цепочка создания } \\
\text { услуги начинается с производителя, } \\
\text { который должен предусматривать } \\
\text { все этапы) }\end{array}$ & $\begin{array}{l}\text { Направляющая (фрормирует направление новых } \\
\text { продуктов и их преимущества) }\end{array}$ \\
\hline Роль консультанта & $\begin{array}{l}\text { Направляющая (продолжает } \\
\text { цепочку рекреационной услуги, } \\
\text { выступает в качестве инструмента } \\
\text { продвижения) }\end{array}$ & $\begin{array}{l}\text { Основная (выступает участником рекреацион- } \\
\text { ной сфреры, от него зависит спрос на товары } \\
\text { и услуги) }\end{array}$ \\
\hline $\begin{array}{l}\text { Формирование } \\
\text { потребительской } \\
\text { ценности }\end{array}$ & $\begin{array}{l}\text { Производитель разрабатывает про- } \\
\text { дукт, выгодный для производства }\end{array}$ & $\begin{array}{l}\text { Консультант подстраивает уже произведенный } \\
\text { продукт под предпочтения потребителя } \\
\text { и передает производителям отзывы и пожелания, } \\
\text { помогает усовершенствовать продукт) }\end{array}$ \\
\hline
\end{tabular}

Проанализировав «постклассическую» модель взаимодействия, можно выделить следующие преимущества для производителей:

- уменьшение трудовых, временны́х и денежных затрат на продвижение рекреационного товара или услуги;

- более эффективное взаимодействие с другими участниками за счет специалистов консалтинговой организации;

- расширение партнерских связей;

- повышение качества обслуживания;

- формирование имиджа социально ответственной компании.

Преимущества этой модели для потребителя:

- предоставление полной информации о товаре или услуге, подобранной индивидуально под потребности;

- предложение комплекса услуг для более эфффективного достижения результата;

- повышение качества обслуживания;

- экономия времени и усилий на поиск информации и изучение продуктов.

Таким образом, в классическом подходе основная роль отводится производителю, который должен выполнять множество фрункций по продвижению рекреационных товаров и услуг, а также организовывать деятельность других участников. Соответственно, для получения хорошей прибыли производителю рекреационной сфреры необходимо затрачивать много ресурсов и усилий, иначе придется ждать, пока другой участник данной сферы возьмет на себя обязанности по организации деятельности этого производителя, что малоприбыльно и нерационально. Следовательно, рекреационная сфера состоит из большого количества производителей, не взаимодействующих между собой, они стараются обособленно развиваться на рынке.

При сравнении моделей взаимодействия участников рекреационной сореры следует учесть такой фрактор, как передача информации. Актуальная информация влияет на результативность деятельности остальных участников. Качество управления может страдать как от недостатка и искажения исходной информации, так и от чрезмерного ее объема, вследствие чего могут возникать перезагрузки в каналах передачи, обработки, хранения информации и связанные с этим дополнительные затраты [14, с. 491]. Участники «классической» модели получают большой поток информации и не всегда передают ее другим. В большинстве случаев информация, пройдя все этапы процесса взаимодействия, теряет свою актуальность и достоверность для участника. В «постклассической» модели консультант проверяет информационные потоки и предотвращает искажение исходной информации от производителя, а также контролирует объем информации, которая необходима потребителю. Благодаря единому центру обслуживания повышается качество управления и улучшается взаимодействие участников рекреационной сферы.

«Постклассическая» модель предлагает освободить производителей от большинства функций рекреационной сферы и возложить их на консалтинговую компанию. Производители смогут направить свои ресурсы и усилия на производство актуальных и качественных товаров и услуг, развивать новые направления бизнеса в рекреацион- 
ной сорере. Консультантам в этой модели будет отведена основная, организаторская роль среди участников. Как было рассмотрено, все участники "постклассической» модели получают больше преимуществ и выгод, чем в «классической» модели взаимоотношений.

Преимущества «постклассической» модели наглядно показаны (см. табл. 3). Применение «постклассической» модели взаимодействия позволит повысить уровень обслуживания, увеличить выгоды участников, улучшить взаимодействия и сформировать новые направления рекреационной сореры. Развитие этой сферы, в отличие от промышленного производства, не требует масштабных сырьевых, трудовых и прочих ресурсов, что дает возможность регионам России внедрять данную модель и развивать эту отрасль народно-хозяйственной системы и является одним из средств вывода региональной экономики из кризиса.

\section{СПИСОК ИСПОЛЬЗОВАННОЙ ЛИТЕРАТУРЫ}

1. Любицева О. О. Рынок туристических услуг / О. О. Любицева. - Киев: Альтерпресс, 2002. - 436 с.

2. Неровня Т. Н. Институциональная специфика рекреационно-ориентированного региона в контексте производства и потребления рекреационной услуги [Электронный ресурс] / Т. Н. Неровня / / Управление экономическими системами. - 2011. - № 9. - Режим доступа: http: / / www.uecs.ru.

3. Программа комплексного социально-экономического развития города Иркутска на 2008-2020 годы / Н. В. Амбросов, Т. Д. Бурменко, И. В. Бычков, М. И. Кузьмин, С. В. Чупров [и др.] ; под ред. М. А. Винокурова, В. И. Самарухи. - Иркутск : Изд-во БГУЭП, 2007. - 413 с.

4. Мамардашвили М. К. Классическая и современная буржуазная философрия (Опыт эпистемологического сопоставления) / М. К. Мамардашвили, Э. Ю. Соловьев, В. С. Швырев / / Вопросы философии. - 1970. № $12 .-$ C. 23-38.

5. Мамардашвили М. К. Классика и современность: две эпохи в развитии буржуазной фрилософии / М. К. Мамардашвили / / Философия в современном мире. Философия и наука. Критические очерки буржуазной философии / под ред. Л. Н. Мигрохина, Э. Г. Эдина, Н. С. Юлина. - М. : Наука, 1972. - С. $28-94$.

6. Автономова Н. С. Статья трех авторов в свете опыта пост-современности: сопоставительные заметки / Н. С. Автономова // На пути к неклассической эпистемологии / отв. ред. В. А. Лекторский. - М. : Ин-т философии РАН, 2009. - 237 с.

7. Тимошина Е. В. Классика, постклассика ... неоклассика: к обоснованию контрпостмодернистской программы в теории права / Е. В. Тимошина / / Известия высших учебных заведений. Правоведение. - 2014. № 4. - С. 6-29.

8. Манхейм К. Консервативная мысль // Диагноз нашего времени : пер. с нем. / К. Манхейм. - М. : Юрист, 1994. - С. 538-540.

9. Пружинин Б. И. Культурно-историческая природа познания и стиль научного мышления / Б. И. Пружинин / / Стиль мышления: проблема исторического единства научного знания : к 80-летию Владимира Петровича Зинченко / под ред. Т. Г. Щедриной. - М. : РОССПЭН, 2011. - С. 28-42.

10. Сачков Ю. В. Эволюция стиля мышления в естествознании / Ю. В. Сачков / / Вопросы философии. 1968. - № 4. - С. 70-81.

11. Флек Л. Возникновение и развитие научного факта: введение в теорию стиля мышления и мыслительного коллектива / Л. Флек. - М. : Идея-Пресс : Дом интеллект. кн., 1999. - 220 с.

12. Борн М. Физика в жизни моего поколения / М. Борн. - М. : Иностр. лит., 1963. - 536 с.

13. Обухова А. А. Модели и варианты оказания ИТ-услуг для малого бизнеса / А. А. Обухова // Вестник Забайкальского государственного университета. — 2013. - № 9. - С. 152-159.

14. Чупров С. В. Информационное обеспечение и управление рисками инновационной деятельности / С. В. Чупров / / Стратегическое управление инновационным потенциалом организации / под ред. А. В. Бабкина. - СПб. : Изд-во С.-Петерб. гос. политехн. ун-та, 2010. - С. 469-503.

\section{REFERENCES}

1. Lyubitseva O. O. Rynok turisticheskikh uslug [Tourism Service Market]. Kiev, Al'terpress Publ., 2002. 436 p.

2. Nerovnya T. N. Institutional Specificity of a Recreation-Oriented Region in the Context of Production and Consumption of Recreational Services. Upravlenie ehkonomicheskimi sistemami = Management of Economic Systems, 2011, no. 9. Available at: http://www.uecs.ru. (In Russian).

3. Ambrosov N. V., Burmenko T. D., Bychkov I. V., Kuz'min M. I., Chuprov S. V. ef al. ; Vinokurov M. A., Samarukha V. I. (eds). Programma kompleksnogo sotsialnoekonomicheskogo razvitiya g. Irkutska na 2008-2020 gody [The Program of Irkutsk Complex Socioeconomic Development in 2008-2020]. Irkutsk, Baikal State University of Economics and Law Publ., 2007. 413 p.

4. Mamardashvili M. K., Solov'ev E. Yu., Shvyrev V. S. Classical and Contemporary Bourgeois Philosophy (Epistemological Comparison). Voprosy filosofii =Issues of Philosophy, 1970, no. 12, pp. 23-38. (In Russian).

5. Mamardashvili M. K. Classics and Contemporaneity: Two Epochs in Development of Bourgeois Philosophy. In Migrokhin L. N., Edin E. G., Yulin N. S. (eds). Filosofiya v sovremennom mire. Filosofiya i nauka. Kriticheskie ocherki burzhuaznoi filosofii [Philosophy in the Modern World. Philosophy and Science. Critical Reflection of Bourgeois Philosophy]. Moscow, Nauka Publ., 1972, pp. 28-94. (In Russian). 
6. Avtonomova N. S. In the Light of Experience of Post Contemporaneity: Comparative Notes (an article by three authors). In Lektorskii V. A. (ed). Na puti k neklassicheskoi epistemologii [Towards Non-Classical Epistemology]. Moscow, Institute of Philosophy, Russian Academy of Sciences Publ., 2009. 237 p. (In Russian).

7. Timoshina E. V. Classics, postclassics ... Neoclassics: to the substantiation of counter-postmodern program in the legal theory. Izvestiya Vysshikh uchebnykh zavedenii. Pravovedenie = Proceedings of Higher Education Institutions. Pravovedenie, 2014, no. 4, pp. 6-29. (In Russian).

8. Mannheim K. Conservative Thought. In Mankheim K. Diagnosis of our time: Wartime essays of a sociologist. London, K. Paul, Trench, Trubner \& co., 1943. 179 p. (Russ. ed.: Mannheim K. Diagnoz nashego vremeni. Moscow, Yurist Publ., 1994. 700 p.).

9. Pruzhinin B. I. Cultural and historical nature of knowledge and the style of scientific thinking. In Shchedrina T. G. (ed.). Stil' myshleniya: problema istoricheskogo edinstva nauchnogo znaniya. K 80-letiyu V. P. Zinchenko [The style of thinking: the problem of historical unity of scientific knowledge. On the $80^{\text {th }}$ anniversary of V.P. Zinchenko]. Moscow, ROSSPEN Publ., 2011, pp. 28-42. (In Russian).

10. Sachkov Yu. V. Evolution of the style of thinking in natural science. Voprosy filosofii =Issues of Philosophy, 1968, no. 4, pp. 70-81. (In Russian).

11. Fleck L. Genesis and Development of a Scientific Fact. The University of Chicago Press, 1979. 155 p. (Russ. ed.: Fleck L. Vozniknovenie i razvitie nauchnogo fakta: vvedenie $v$ teoriyu stilya myshleniya i myslitel' nogo kollektiva. Moscow, Ideya-Press, Dom intellektual'noi knigi Publ., 1999. 220 p.).

12. Born M. Physics in My Generation: A Selection of Papers. London, Pergamon, 1956. (Russ. ed.: Born M. Fizika v zhizni moego pokoleniya. Moscow, Inostrannaya literatura Publ., 1963. 536 p.).

13. Obukhova A. A. Models and Options of Rendering IT-Services for Small Business. Vestnik Zabaikal'skogo gosudarstvennogo universiteta = Zabaikalye State University Journal, 2013, no. 9, pp. 152-159. (In Russian).

14. Chuprov S. V. Information and Innovation Risk Management. In Babkin A. V. (ed.). Strategicheskoe upravlenie innovatsionnym potentsialom organizatsii [Strategic Management of a Company's Innovative capacity]. Peter the Great Saint-Petersburg Polytechnic University Publ., 2010, pp. 469-503. (In Russian).

\section{Информация об авторе}

Бархатова Анна Михайловна - аспирант, кафедра менеджмента, маркетинга и сервиса, Байкальский государственный университет, 664003, г. Иркутск, ул. Ленина, 11, e-mail: anitabar@list.ru.

\section{Для цитирования}

Бархатова А. М. Модели взаимодействия участников рекреационной сферы с помощью консалтинга / А. М. Бархатова // Известия Байкальского государственного университета. - 2017. - T. 27, № 4. - C. 515-522. - DOl: $10.17150 / 2500-2759.2017 .27(4) .515-522$.

\section{Author}

Anna M. Barkhatova - PhD student, Department of Management, Marketing and Service, Baikal State University, 11 Lenin St., 664003, Irkutsk, Russian Federation, e-mail: anitabar@list.ru.

\section{For citation}

Barkhatova A. M. Interaction Models of Recreational Industry Participants by Means of Consulting Services. Izvestiya Baykal'skogo gosudarstvennogo universiteta $=$ Bulletin of Baikal State University, 2017, vol. 27, no. 4, pp. 515-522. DOl: 10.17150/25002759.2017.27(4).515-522. (In Russian). 